\title{
O USO DE RECURSOS MIDIÁTICOS ATRAVÉS DE SMARTPHONES NO APOIO EDUCACIONAL
}

\author{
THE USE OF MEDIA RESOURCES THROUGH CELLULAR DEVICES IN \\ EDUCATIONAL SUPPORT
}

\section{Recebimento:13/10/2017- Aceite: 10/11/2018- Publicação: 28/01/2018 Processo de Avaliação: Double Blind Review}

João Carlos Lopes Fernandes ${ }^{1}$

Doutor em Engenharia Biomédica

Centro Universitário ENIAC - NUPE - Núcleo de Pesquisa ENIAC

Faculdade de Tecnologia de São Caetano

Instituto MAUA de Tecnologia

joao.carlos@eniac.edu.br

\section{RESUMO}

A presença de recursos midiáticos na educação está a cada dia se tornando mais imprescindível nas salas de aula convencionais; estes recursos devem ser bem explorados pelos professores. Dentre os recursos midiáticos existentes os smartphones são os mais utilizados pelos alunos, pois os modelos mais atuais são verdadeiros computadores em tamanho reduzido. Outro fator que aumentou a quantidade de smartphones, foi sua redução de custo e o aparecimento de planos de Internet com preços mais populares. Mas de qualquer forma a utilização de smartphones sempre foi proibida nas salas de aula, seja por meios de leis estaduais ou municipais ou pelo regimento interno de algumas instituições. Atualmente, estes aparelhos deixaram de ser visto apenas como um equipamento para diversão e entretenimento e passou a fazer parte do rol dos recursos que podem ser utilizados para o apoio educacional, pois quando bem utilizados, auxiliam no processo de aprendizagem. Para que estes recursos possam ser bem utilizados, a instituição de ensino deve investir em infraestrutura, criando redes sem fio mais eficientes e fornecer treinamento aos professores que serão os principais mediadores junto aos alunos.

Palavras-chave: Recursos Midiáticos; Smartphones; Apoio Educacional; Aprendizagem.

\footnotetext{
${ }^{1}$ Autor para correspondência: Centro Universitário ENIAC, R. Força Pública, 89, Centro - Guarulhos, São Paulo, CEP: 07012-030, Brasil.
}

Revista ENIAC Pesquisa, Guarulhos (SP), V.7, n.1, jan.- jun. 2018. 


\section{ABSTRACT}

The presence of media resources in education is becoming more and more essential in conventional classrooms; These resources should be well explored by teachers. Among the existing media resources, mobile devices are the most used by students, since the most current models are true computers in small size. Another factor that increased the number of handsets, was its cost reduction and the appearance of Internet plans with more popular prices. But in any case, the use of cell phones has always been prohibited in classrooms, either through state or municipal laws or by the bylaws of some institutions. Nowadays, these devices are no longer seen as just an equipment for fun and entertainment and it is part of the list of resources that can be used for educational support, because when used well, they aid in the learning process. For these resources to be well used, the educational institution must invest in infrastructure, create more efficient wireless networks and provide training to the teachers who will be the main mediators to the students.

Keywords: Media Resources; Cellphone; Educational Support; Learning.

\section{INTRODUÇÃO}

Existe uma grande preocupação dos educadores em modificar as tradicionais aulas para um modelo onde o aluno se torne mais participativo e seja o centro da aprendizagem. Atualmente os recursos midiáticos estão mais presentes na educação, eles começaram com o uso de TV, rádio e agora os smartphones já fazem parte das possíveis soluções. Pode-se verificar um aumento gradativo do número de alunos que utilizam smartphones, mas principalmente por se tratar de uma geração que nasceu na era da Internet, também conhecida por "geração polegar", devido à utilização constante do aparelho para comunicar-se com seus amigos e familiares por meio das redes sociais e serviços de mensagens de texto. Com a facilidade no uso, os alunos têm criado novos usos por meio da aprendizagem não formal, ou seja, sem a mediação de professores, fator decorrente da proibição do uso dos aparelhos na sala de aula. Segundo (D’AMBRÓSIO, 2001, p. 37):

É preciso substituir os processos de ensino que priorizam a exposição, que levam a um receber passivo do conteúdo, através de processos que não estimulem os alunos à participação. É preciso que eles deixem de ver a "ciência" como um produto acabado, cuja transmissão de conteúdo é vista como um conjunto estático de conhecimentos e técnicas.

Aparentemente existe uma grande insatisfação por boa parte dos alunos em relação a aulas "tradicionais", decorrente da enorme quantidade de informação transmitida pelo professor, ou seja, aulas expositivas nas quais são utilizados apenas o quadro-negro e o giz e

Revista ENIAC Pesquisa, Guarulhos (SP), V.7, n.1, jan.- jun. 2018. 
o aluno é apenas um receptor de conteúdo. A simples questão do aprender por aprender já faz parte do passado, atualmente os alunos necessitam ser convencidos do motivo de cada aula, para que, e o porquê precisam saber aquele determinado assunto. O smartphones é um tema bem discutido no âmbito educacional, em reuniões pedagógicas, mesmo com as leis de proibição dentro das salas de aula, os alunos continuam a utilizá-lo. Eles ultrapassaram a função de telefones e se transformaram em pequenos computadores. Mesmo proibindo o uso de smartphones nas aulas, com as facilidades da Internet, quando um professor está explicando um determinado conteúdo, muitos alunos já estão o consultando de forma online através dos buscadores, como exemplo, o Google e tirando suas próprias conclusões. Sem o uso de recursos midiáticos por parte dos professores, por mais preparado que ele esteja é quase que impossível suprir todas as dúvidas do conteúdo consultado pelos alunos e assim conseguir prender a atenção na aula que está sendo meramente guiada por lousa e giz. A utilização de smartphones já faz parte do cotidiano dos alunos que já nasceram na no mundo informatizado. Muitas vezes nos deparamos com crianças ainda não alfabetizadas utilizando smartphones para as mais diversas funções, como jogar, pintar, assistir filmes entre outros recursos disponibilizados pelo aparelho, estas crianças crescem com os aparelhos nas mãos que os acompanham desde da escola infantil.

De acordo com os (PCNs, 2000, p. 24):

As novas tecnologias da comunicação e da informação permeiam o cotidiano, independente do espaço físico, e criam necessidades de vida e convivência que precisam ser analisadas no espaço escolar. A televisão, o rádio, a informática, entre outras, fizeram com que os homens se aproximassem por imagens e sons de mundos antes inimagináveis. (...) Os sistemas tecnológicos, na sociedade contemporânea, fazem parte do mundo produtivo e da prática social de todos os cidadãos, exercendo um poder de onipresença, uma vez que criam formas de organização e transformação de processos e procedimentos.

Desta forma encontramos crianças com idade inferior a 7 anos, configurando os smartphones de seus pais, em uma primeira análise, isto nos parece muito interessante, pois a criança está interagindo e resolvendo problema, mas na verdade precisamos utilizar todo o "potencial" para ensina-la a "aprender a aprender". Já que os alunos gostam tanto de seus smartphones, que são seus companheiros inseparáveis, os professores em suas aulas devem utilizar isto a seu favor, por que não aproveitar essa oportunidade e criar uma aula mais

Revista ENIAC Pesquisa, Guarulhos (SP), V.7, n.1, jan.- jun. 2018. 
interativa e divertida? Os professores devem aproveitar esta paixão e preparar aulas mais empolgantes, buscando atrair a atenção dos alunos com atividades ligadas aos smartphones, De acordo com (SABADIN,2014, p. 44)

Os(as) alunos(as) da era dos dispositivos móveis interagem com seus colegas, durante as aulas por intermédio do smartphone, a interação entre eles mudou, pois ao invés de jogar papel no(a) colega, para chamar atenção, passaram a criar grupos de conversa online para interagir, passar respostas das atividades, tarefas e até como uma forma inovadora de passar "cola nas provas". O sistema pode até proibir o uso dos dispositivos em sala de aula, em casos extremos, são colocados bloqueadores de smartphones, mas os(as) alunos(as) sempre encontram uma forma de burlar o sistema. No final dessa disputa, a escola fica com a internet bloqueada e os(as) alunos(as) com seus smartphones funcionando. Por que não utilizar esses dispositivos móveis que os alunos "conhecem" em sala de aula?

Existe ainda muita resistência por parte de alguns professores mais "tradicionais" que tentam simplesmente impedir que os alunos utilizem seus smartphones nas aulas, justificando que esta utilização desvia a atenção ao conteúdo que está sendo exposto, pois possui um caráter de informalidade, de certo ponto isto fundamenta as críticas quanto ao uso do smartphone; com certeza o uso de smartphones deve ser controlado, mas não proibida, pois (LIBANEO, 2000, p. 73):

[...] define a educação informal como processo continuo de aquisição de conhecimentos e competências que não se localizam em nenhum quadro institucional, acrescentando ainda o seu caráter não-intencional (...) utilizasse do termo para identificar práticas educativas decorrentes da impregnação do meio ambiente perante o qual os indivíduos precisam adaptar-se. Entendendo, todavia, que o termo informal é mais adequado para indicar a modalidade de educação que resulta do clima em que os indivíduos vivem, envolvendo tudo o que do ambiente e das relações socioculturais e políticas impregnam a vida individual e grupal. Tais fatores ou elementos informais da vida social afetam e influenciam a educação das pessoas de modo necessário e inevitável, porém não atuam deliberadamente, metodicamente, pois não há objetivos preestabelecidos conscientemente

Quando o professor consegue utilizar os smartphones dos alunos em uma atividade em sala de aula, com certeza os alunos ficam mais empolgados em participar das discussões, pois eles passam de meros receptores para compartilhadores de conhecimento. Com a utilização, por exemplo de jogos, filmes e ferramentas de busca as aulas podem se tornar bem mais divertidas. As instituições e os professores sempre precisam se modernizar a fim de acompanhar o ritmo dos alunos. Mas será que eles estão preparados para estas mudanças? Pois os professores precisam ser atualizados, segundo (RÖRIG, 2013, p. 93)

Revista ENIAC Pesquisa, Guarulhos (SP), V.7, n.1, jan.- jun. 2018. 
O professor também necessita de atualização permanente, buscar sempre informações, saber o que está acontecendo, estar consciente da relação entre os diferentes saberes. Saber somente sobre a sua área de atuação não é mais suficiente para atender as necessidades dos alunos. Isto não quer dizer que o professor precise saber tudo, mas sim, saber o que o aluno quer conhecer. O processo educativo precisa estar vinculado ao contexto social, em que o sujeito - aluno - está inserido. Isso irá implicar em conhecer e usar instrumentação eletrônica, bem como outros recursos pedagógicos.

\section{RECURSOS MIDIÁTICOS UTILIZADOS NAS AULAS}

Quando as aulas utilizam recursos midiáticos elas têm vida mais longa e podem ser adaptadas para vários tipos de alunos, a mesma aula com pequenas adaptações pode ser utilizada em várias faixas etárias e permitir inúmeros níveis de aprendizagem, ou seja, dependendo da profundidade que o professor abrange o assunto o mesmo material poderá ser utilizado do ensino fundamental até o superior. Desta forma o trabalho do professor fica bem mais simples, e através do retorno dos alunos, ele conseguirá medir o seu nível de eficácia. (SABADIN, 2014, p.83) afirma que,

No contexto da tecnologia e da globalização, a informação se processa mais rápida e instantaneamente. Resta pensar sobre o perfil cognitivo do(a) leitor(a) que transita pelas diversas redes sociais e qual processo educativo seria capaz de aprimorar conhecimentos advindos também das redes informacionais, de modo a fazer com que o(a) aluno(a) não apenas se aproprie das informações, mas venha a questioná-las como sujeito de suas próprias ações sociais.

É importante, que exista não apenas investimentos das instituições em recursos midiáticos, os professores também devem ser capacitados, pois para auxiliar os alunos o ele deverá dominar as tecnologias envolvidas no processo. Existem muitos programas disponíveis para montagem de atividades interativas inclusive jogos; porém, alguns professores ainda não sabem como utilizá-los. Fazer o uso de recursos midiáticos em sala de aula é o menor dos desafios para os professores, o problema e a forma de tornar a aula mais envolvente, interativa e criativa, pois não adianta usar os recursos e não "convencer" os alunos do que devem aprender. $\mathrm{O}$ simples fato de transferir a tarefa do quadro-negro para o smartphones sem altera o formato da aula não vai adiantar muito. A metodologia utilizada pelo professor também deve ser repensada e modernizada, pois segundo (MORAN, 2007, p.139):

Revista ENIAC Pesquisa, Guarulhos (SP), V.7, n.1, jan.- jun. 2018. 
Quanto mais mergulhamos na sociedade da informação, mais rápidas são as demandas por respostas instantâneas. As pessoas, principalmente as crianças e os jovens, não apreciam a demora, querem resultados imediatos. Adoram as pesquisas síncronas, as que acontecem em tempo real e que oferecem respostas quase instantâneas. Os meios de comunicação, principalmente a televisão, vêm nos acostumando a receber tudo mastigado, em curtas sínteses e com respostas fáceis. $\mathrm{O}$ acesso às redes eletrônicas também estimula a busca online da informação desejada. É uma situação nova no aprendizado.

Quando se aborda recursos midiáticos incluem-se a lousa interativa, o computador, o uso de smartphones nas aulas entre outros recursos, mas independe do recurso utilizado, o objetivo principal deve sempre ser a aprendizagem colaborativa. As professoras Vivian Magalhães e Vanessa Amorim, em seu livro "Cem aulas sem tédio", relatam que os professores devem encarar seus medos de mudança e utilizar os recursos midiáticos disponíveis como apoio a suas aulas. Elas deixam bem claro que os professores jamais serão substituídos pela tecnologia, que aparentemente é o principal "medo" da maioria deles; isto muitas vezes cria uma barreira nas mudanças necessárias para a transformação de suas aulas. (MAGALHÃES, 2016)

Quando a Internet é bem utilizada em sala de aula possuímos um aluno mais centrado na aprendizagem, pois ela já faz parte do seu cotidiano. Além do mais a Internet é uma ferramenta poderosíssima na aprendizagem, pois acelera o acesso à informação e incentiva o aluno a buscar o conhecimento. Outro fator interessantíssimo é que, a maioria dos materiais disponibilizados na Internet, sendo filmes ou documentários, não respeitam uma sequência linear de aprendizado e despertam assim nos alunos o senso de autocrítica.

Segundo (VYGOTSKY,1984), a zona de desenvolvimento proximal (ZDP) que pode ser criada com o uso da Internet, proporciona um envolvimento completo e uma interação ampla do aluno com o mundo que o cerca, criando situações desafiadoras e com isso existirá a aprendizagem efetiva dos conteúdos, ou seja, o conhecimento começa a fazer parte de sua vida. O papel dos professores, segundo o ZDP, é o de ser mediador, auxiliando os alunos a alcançarem seus objetivos educacionais, aproveitando todos os benefícios que os recursos midiáticos, como o smartphones podem proporcionar. Desta forma o professor deve trazer para sua aula os elementos da realidade dos alunos, diferentes da linguagem tradicional da escola, que é normalmente o padrão escrito em lousa ou projeta em telas com enormes textos

Revista ENIAC Pesquisa, Guarulhos (SP), V.7, n.1, jan.- jun. 2018. 
criados em um editor de texto ou softwares para criação de apresentações. Independentemente dos recursos midiáticos utilizados, o professor sempre deverá ser capaz de mediar a aprendizagem, de forma atrativa, divertida e interessante para os alunos. Os recursos midiáticos, bem mais do que sanar a curiosidade dos alunos devem prepará-lo para os desafios fora da escola. São muitos os benefícios oferecidos com o uso de recursos midiáticos na escola, contudo, é preciso realizar um planejamento antes de utiliza-los.

\section{OS SMARTPHONES NA SALA DE AULA}

É necessário existirem regras básicas entre alunos e professores, ou seja, criar uma ponte entre os professores, smartphones e alunos, para que a aprendizagem realmente aconteça e se torne mais rica e estimulante. Quando o professor reconhece a importância da incorporação desses recursos na prática pedagógica, ele incentiva a reflexão e o debate que cerca os recursos midiáticos e o uso de smartphones na educação. Segundo (MORAN, 2007, p.89)

O professor tem esses dois papéis: ajudar na aprendizagem de conteúdos e ser um elo para uma compreensão maior da vida, de modo que encontremos formas de viver que nos realizem e desenvolvam nossas capacidades. Isso não depende da tecnologia, mas da atitude profunda do educador e do educando, de ambos quererem aprender. A tecnologia pode ser útil para integrar tudo que eu observo no mundo no dia-a-dia e para fazer disso objeto de reflexão. Ela me permite fazer essa ponte, trazer os conteúdos de forma mais ágil e devolvê-los de novo ao cotidiano, possibilitando a interação entre alunos, colegas e professores.

Ao contrário do que acontece com os cadernos, apostilas e livros, que muitas vezes os alunos só observam no dia seguinte, ou até mesmo esquecem de fazer suas tarefas, os smartphones continua sendo utilizado após o final da aula, ele é um companheiro inseparável. Desta forma, utilizar o smartphones em uma sala de aula pode se tomar uma forma bem interessante de atrair a atenção dos alunos e aumentar as possibilidades na busca pelo conhecimento, além de proporcionar aos professores mais uma forma de tornar suas aulas mais interessantes e assim melhorar a aprendizagem e o contato com os alunos. Nesse novo cenário, os professores e alunos podem compartilhar materiais para estudo através de recursos disponibilizados na Internet, para servirem de referência e auxiliarem em várias tarefas. Uma grande vantagem na utilização é que os alunos podem tirar dúvidas uns com os

Revista ENIAC Pesquisa, Guarulhos (SP), V.7, n.1, jan.- jun. 2018. 
outros por meio de mensagens instantâneas ou grupos de discussão, compartilhando o conhecimento e incentivando o senso de trabalho em equipe.

Em países mais desenvolvidos, o investimento em tecnologias para mobilidade educacional é cada vez maior, como na Inglaterra e nos Estados Unidos, por exemplo, a verba para a esta finalidade é bem mais elevada em comparação com outros países. Sendo assim desenvolver tecnologias educacionais para a mobilidade que auxiliem no processo de aprendizagem, estão indo ao encontro que a utilização dos smartphones na sala de aula definitivamente é uma vertente para aprendizagem. Atualmente existem diversos aplicativos e jogos educacionais direcionados à smartphones, muitos deles já foram desenvolvidos utilizando técnicas de gamification ${ }^{2}$, que é a estratégia de interação entre pessoas e empresas com base no oferecimento de incentivos que estimulem o engajamento do público com as marcas de maneira lúdica. Muitas empresas especializadas em softwares para a área da educação já estão desenvolvendo suas soluções nesta perspectiva. A possibilidade do controle de cronogramas de provas, entrega de atividades e a disponibilização de conteúdos extraclasse, por exemplo, também deve ser levada em consideração quando a instituição, busca ser mais arrojada e utilizar smartphones em seu plano pedagógico. O Google, por exemplo, que já é considerado uma importante ferramenta de auxílio aos alunos, ele possui uma linha de aplicativos totalmente voltada ao ensino: o Google for Education, que já está em utilização em varais instituições, como exemplo o Centro universitário ENIAC, que possui todas as funcionalidades deste programa educacional e disponibiliza dentre as várias mídias possíveis, acesso através dos smartphones aos alunos e professores.

Imagine, por exemplo, os alunos em uma aula de geografia sobre a Europa, o professor poderia solicitar que eles busquem seus smartphones os dados recentes sobre demografia, política, aspectos sociais e curiosidades inerentes aos países pertencentes a este continente. Após localizarem as informações eles podem compartilhar com seus colegas e com o professor e aí começar a discussão dos resultados.

\footnotetext{
${ }^{2}$ Estratégia de interação entre pessoas e empresas com base no oferecimento de incentivos que estimulem o engajamento do público com as marcas de maneira lúdica.
}

Revista ENIAC Pesquisa, Guarulhos (SP), V.7, n.1, jan.- jun. 2018. 
Durante as aulas muitos alunos acessam as redes sociais e trocam informações instantâneas entre si, com o uso do Facebook e Whatsapp, muitas escolas bloqueiam o acesso dentro de suas redes sem fio, mas isto não adianta nada, pois os alunos acessam utilizando seus pacotes de dados, aumentado assim ainda mais a dispersão das aulas. Mas porque não utilizar estes recursos como apoio educacional, podendo ser direcionadas para uso em sala de aula. A criação de grupos de discussão e debates sobre determinado assunto é um bom exemplo. Além de incentivar uma maior participação do aluno, eles incentivaram a realização de atividades fora da sala de aula. A escola, a classe, a turma, a disciplina pode possuir seu Facebook e criar várias atividades educacionais.

Outra forma de utilizar os smartphones de forma consciente na sala de aula é por meio da produção de conteúdo digital, ou seja, usando a câmera para tirar fotos e gravar vídeos que serão utilizados durante as aulas. O professor pode propor atividades que explorem vários recursos dentro da própria escola ou mesmo na casa do aluno. A realização de atividades em grupo e visitas guiadas a museus e parques também podem ser propostas interessantes.

Desta forma o uso do smartphones na escola como ferramenta de apoio educacional, pode possibilitar uma forma inovadora de aprendizagem.

Além das possibilidades digitais que os smartphones oferecem e o acesso à Internet, já existem muitas ferramentas educacionais gratuitas, desenvolvidas com a função de auxiliar alunos e professores.

O Kahoot!, por exemplo é uma plataforma de aprendizagem baseada em jogos, utilizada como tecnologia educacional em salas de aula para apoio a aprendizagem. Ele é utilizado por milhões de pessoas em mais de 100 países, inclusive no Brasil. Seus jogos de aprendizagem são chamados de "kahoots" que são apresentados em forma de questões de múltipla escolha que podem ser criadas por qualquer professor e não são restritas, outro detalhe importante é que o número de perguntas é definido pelo professor, sendo possível adicionar vídeos, imagens e diagramas nas perguntas com o intuito de ampliar o envolvimento com o aluno. O Kahoot! é gratuito e pode ser jogado usando em qualquer dispositivo móvel (smartphones), desktop ou laptop que se conectem à internet e utilizem um

Revista ENIAC Pesquisa, Guarulhos (SP), V.7, n.1, jan.- jun. 2018. 
navegador WEB ou um app no caso dos smartphones. Outro detalhe importante na criação dos questionarios, é que o professor pode defini-los como lição de casa para seus alunos e realizar avaliações instantâneas, o que permitem o acompanamento do progresso da aprendizagem, através de relatórios online. (KAHOOT!, 2017)

A Figura 1, ilustra a tela do Kahoot!

Figura 1: Tela do Kahoot!

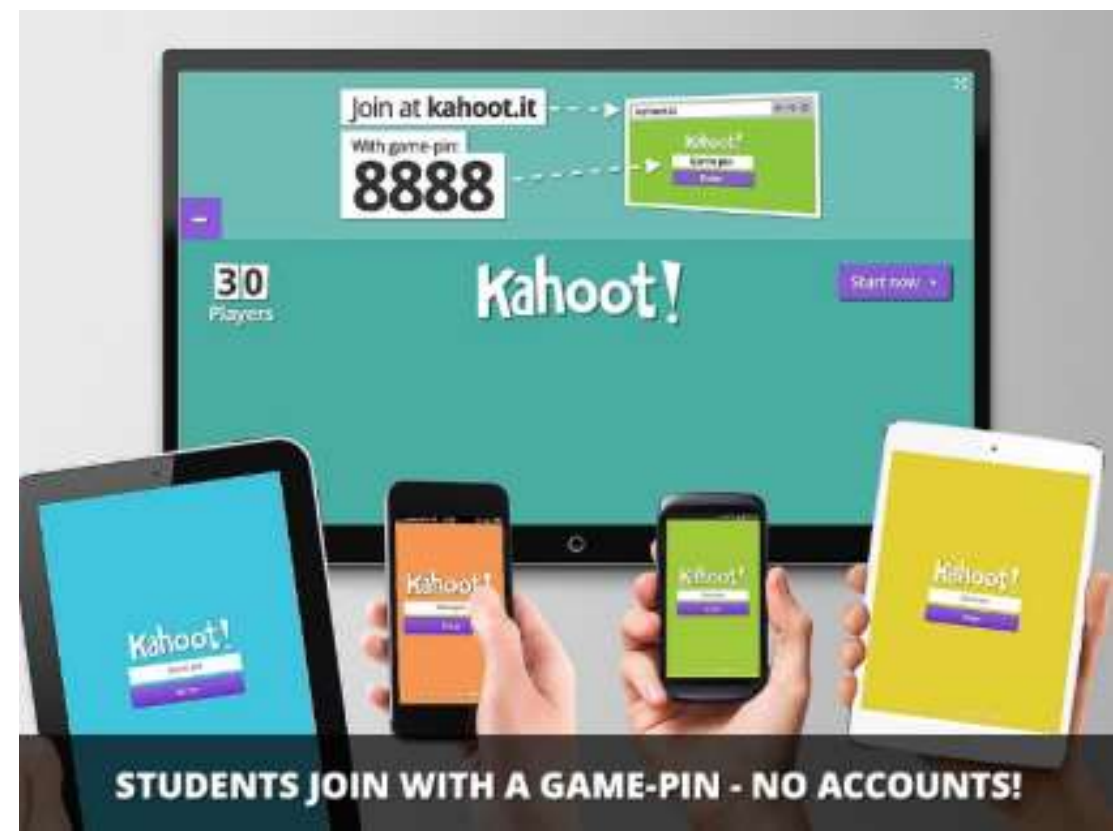

Fonte: https://www.scoop.it/t/geography-education/

A tabela 1, apresenta 10 (dez) soluções especificamente desenvolvidas para o uso em smartphones.

Revista ENIAC Pesquisa, Guarulhos (SP), V.7, n.1, jan.- jun. 2018. 
Tabela1: Aplicativos educacionais para uso em smartphones

\begin{tabular}{|c|c|}
\hline Aplicativo & Função \\
\hline Andie Graph & $\begin{array}{l}\text { Simula da calculadora TI-83. Inclui todas as funcionalidades de } \\
\text { uma calculadora gráfica e alguns recursos extras. }\end{array}$ \\
\hline Study Checker & $\begin{array}{l}\text { Controle de quanto tempo o aluno passa estudando, além de } \\
\text { permitir a programação de pausas e outros recursos. }\end{array}$ \\
\hline Speed Reading & $\begin{array}{l}\text { Auxilia no desenvolvimento do processo de leitura dinâmica. A } \\
\text { ferramenta oferece provas de texto específicas, além de análises } \\
\text { sobre o seu desempenho. }\end{array}$ \\
\hline School Timetable Deluxe & $\begin{array}{l}\text { Ajuda o aluno a estruturar as diretrizes do seu dia escolar. É útil } \\
\text { tanto para professores quanto para estudantes. Pode ser usado para } \\
\text { gerenciamento do currículo escolar, notas e horários. }\end{array}$ \\
\hline Studyblue Flashcards & $\begin{array}{l}\text { Funciona como cartões de fichamento que ajudam a desenvolver o } \\
\text { aprendizado em diversas áreas. }\end{array}$ \\
\hline Nearpod & $\begin{array}{l}\text { Permite compartilhar realizar apresentações multimídia nos seus } \\
\text { smartphones. }\end{array}$ \\
\hline TooNoisy & $\begin{array}{l}\text { Detector de ruído que mostra um gráfico e toca um alarme caso o } \\
\text { nível de barulho supere valores especificados pelo professor. } \\
\text { Quando o ruído aumenta, a imagem é modificada. }\end{array}$ \\
\hline Trello & $\begin{array}{l}\text { É um caderno virtual em que o aluno pode anotar ideias, tarefas, } \\
\text { imagens ou links. }\end{array}$ \\
\hline Socrative & $\begin{array}{l}\text { Provas na internet, que podem ser realizadas pelo smartphone, } \\
\text { tablet ou computador. Tem integração com o Google Drive e } \\
\text { possui jogos educativos. }\end{array}$ \\
\hline Remind & Responde mensagens aos alunos e pais ao mesmo tempo. \\
\hline
\end{tabular}

Fonte: Elaborado pelo autor, 2017.

\section{CONSIDERAÇÕES FINAIS}

Fica evidente que somente utilizar a lousa, o giz, os cadernos, os livros e as apostilas não são mais suficientes para manter os alunos motivados e interessados em aprender. Muitas instituições utilizam recursos computacionais buscando complementar e motivar a aprendizagem dos alunos.

Os smartphones fazem parte do cotidiano da maioria dos adolescentes. Desta forma, proibir o seu uso em uma sala de aula pode desmotivar os alunos e criar ainda muita

Revista ENIAC Pesquisa, Guarulhos (SP), V.7, n.1, jan.- jun. 2018. 
insatisfação com a aula. Sendo assim os professores devem tirar proveito desta poderosa ferramenta e atrair a atenção do aluno para a aprendizagem. Quando bem planejada a aula o uso do smartphone pode se tornar um rico instrumento de apoio a aprendizagem. A grande maioria dos smartphones atuais possui inúmeros recursos que podem ser utilizados nesse sentido: câmeras, gravador de voz, mapas, além de, é claro, o acesso à Internet. Estar conectado dentro de uma sala de aula não necessariamente significa a distração e perda de foco dos alunos. Quando bem direcionada a utilização o aluno acaba se tornando o protagonista de sua aprendizagem. Por meio deles, é possível incrementar as aulas e oferecer conteúdo mais interativos e motivadores que despertem o interesse do aluno em participar do processo de aprendizagem.

Mas alguns cuidados devem ser tomados, pois o uso de smartphones em sala de aula sem nenhuma estratégia ou tipo de controle não é, absolutamente, recomendado. O ideal é que o professor consiga, desenvolver práticas pedagógicas que o insiram de forma lúdica nas aulas. Por isso, é fundamental que na proposta pedagogia já conste atividades que necessitem do uso dos smartphones.

Contudo, pelo fato dos smartphones possuírem múltiplas finalidades, alguns podem não ser pedagogicamente corretos, sendo necessário um estudo mais aprofundado sobre suas diversas potencialidades e opções para uma correta utilização.

\section{REFERÊNCIAS}

BRASIL. Parâmetros Curriculares Nacionais (PCN). Brasília: MEC/SEF 19982000.

D’AMBRÓSIO, U. Educação Matemática: da Teoria à Pratica. Campinas: Papirus, 2001.

KAHOOT!. WHAT IS KAHOOT!? (2017). Disponível em: https://kahoot.com/what-iskahoot/, acesso 08 dez. 2017

LIBÂNEO, J. C. Produção de saberes na escola: suspeitas e apostas. In: CANDAU, V. M. (Org.). Didática, currículo e saberes escolares. Rio de Janeiro: DP \& A, 2000. p. 11-45.

Revista ENIAC Pesquisa, Guarulhos (SP), V.7, n.1, jan.- jun. 2018. 
MAGAlHÃES, V.; AMORIM, V. Cem aulas sem tédio. Porto Alegre:ed. Instituto Padre Reus, 2016

MORAN, J. M. A educação que desejamos: novos caminhos e como chegar lá. 2. ed. Campinas: Papirus, 2007

RÖRIG, C., BACKES L. O professor e a tecnologia digital na sua prática educativa (2013). Disponível em:

www.pgie.ufrgs.br/alunos_espie/espie/luciana/public_html/mara.doc, acesso 08 nov. 2017

SABADIN, M. N. O Ensino da Língua Inglesa por meio das Mídias Digitais de

Informação. In: Anais do II Seminário Internacional e III Nacional em Estudos da Linguagem - SNEL. Unioeste, Cascavel - PR, 2014. ISSN 2178-8200. Disponível em: http://snel.fnix.com.br/2014/anais. Acesso em 16 abr. 2017

VYGOTSKY, L.S. Formação social da mente. São Paulo: Martins Fonte, 1984.

Revista ENIAC Pesquisa, Guarulhos (SP), V.7, n.1, jan.- jun. 2018. 